DOI: https://doi.org/10.15688/lc.jvolsu.2017.4.15

UDC 346.62

LBC 67.402

\title{
PROPORTIONAL REGULATION OF THE RUSSIAN BANKING SYSTEM: LEGAL FUNDAMENTALS AND DEVELOPMENT PROSPECTS
}

\author{
Svetlana M. Mironova \\ Volgograd Institute of Management - Volgograd branch of RANEPA, Volgograd, Russian Federation
}

Introduction: currently the Russian banking system is in the reform process that determines the need for the scientific understanding of the effects of separating banks into banks with a general license and banks with a basic license. The aim of this work is to study the nature of the proportional regulation of the Russian banking system, wherefore, there are the following tasks: to consider the formation of the Russian banking system at the present stage, to investigate the transition to the proportional regulation of the banking system; to determine the development prospects of the Russian banking system because of the transition to the proportional regulation. The methodological framework for the research is both the general scientific and special legal methods of cognition. Results: the researched scientific approaches to studying the proportional regulation of the banking system allowed developing the author's viewpoint grounded in the work and determining the development prospects of the banking system in Russia. Conclusions: it is necessary to predict that using the proportional regulation of the banking system, as applied by the legislator, will inevitably lead to even greater strengthening of the role of big, system-forming banks and increasing the concentration of financial resources within a narrow circle of subjects of the banking sector. There increases the state's influence on banking, which in turn indicates the need to strengthen the state responsibility for the errors in the decisions on developing and strengthening the banking system. Providing support to the systemically important banks at the expense of the budget funds, the state must prove the feasibility and effectiveness of such decisions.

Key words: financial system, banking system, Central Bank of Russia, banking legislation, proportional control, systemically important banks, banks with general license, banks with basic license.

УДК 346.62

ББК 67.402

\section{ПРОПОРЦИОНАЛЬНОЕ РЕГУЛИРОВАНИЕ БАНКОВСКОЙ СИСТЕМЫ РОССИИ: ПРАВОВЫЕ ОСНОВЫ И ПЕРСПЕКТИВЫ РАЗВИТИЯ}

\author{
Светлана Михайловна Миронова \\ Волгоградский институт управления - Волгоградский филиал РАНХиГС, г. Волгоград, Российская Федерация
}

Введение: в настоящее время российская банковская система находится в процессе реформирования, что предопределяет необходимость научного осмысления последствий разделения банков на банки с универсальной лицензией и банки с базовой лицензией. Целью работы является исследование сущности пропорционального регулирования российской банковской системы, в связи с чем выделяются следующие задачи: рассмотреть становление российской банковской системы на современном этапе; исследовать переход к пропорциональному регулированию банковской системы; определить перспективы развития банковсву исследования составили как общенаучные, так и специальные юридические методы познания. Результ таты: исследованные научные подходы к вопросу изучения пропорционального регулирования банковской системы позволили выработать обоснованную в работе авторскую позицию и определить перспективы 뭉 развития банковской системы в России. Выводы: следует прогнозировать, что применение пропорционального регулирования банковской системы в том виде, который применен законодателем, неизбежно приведет (?) к еще большему усилению роли крупных, системно значимых банков и росту концентрации финансовых 
ресурсов в рамках узкого круга субъектов банковского сектора. Возрастает влияние государства на работу банков, что в свою очередь свидетельствует о необходимости усиления ответственности государства за ошибки при принятии решений по развитию и укреплению банковской системы. Оказывая поддержку системно значимым банкам за счет средств бюджета, государство должно обосновывать целесообразность и эффективность принятия таких решений.

Ключевые слова: финансовая система, банковская система, Центральный банк РФ, банковское законодательство, пропорциональное регулирование, системно значимые банки, банки с универсальной лицензией, банки с базовой лицензией.

\section{Введение}

Банковская система, являясь элементом финансовой системы, оказывает существенное влияние на развитие иных финансово-правовых институтов. При этом большое значение приобретает финансово-правовая политика в отношении российских банков, оказание поддержки системно значимым банкам. Возрастает влияние государства на кредитные организации. В настоящее время российская банковская система находится в процессе реформирования, что предопределяет необходимость научного осмысления последствий разделения банков на банки с универсальной лицензией и банки с базовой лицензией.

\section{Становление \\ российской банковской системы на современном этапе}

В финансовом праве традиционно одним из элементов финансовой системы называют банковский кредит. С.В. Рыбакова указывает на взаимодействие банковского кредита с бюджетной системой, страхованием, финансами предприятий [10]. Важность для экономики эффективного функционирования банковской системы предопределяет активное государственное участие в формировании денежно-кредитных институтов. Следует согласиться с Е.В. Черниковой, что «государство, оказывая постоянное активное правовое и иное воздействие на поведение субъектов банковской деятельности, то есть организуя ее посредством правового регулирования, определяет характер и направленность ее эволюции, производит отбор банковских инструментов и институтов, наиболее адекватных конкретной экономической стадии и уровню развития финансовой системы государства и общества» [11].
Структура банковской системы Российской Федерации определена Федеральным законом от 02.12.1990 № 395-1 (ред. от 26.07.2017) «О банках и банковской деятельности», в соответствии с которым банковская система Российской Федерации является двухуровневой: первый уровень представлен Банком России, второй - кредитными организациями и представительствами иностранных банков.

В отличие от опыта других государств (например, США и Германии), в которых представлена многоуровневая банковская система, российское законодательство первоначально разделило второй уровень банковской системы лишь на банки и небанковские кредитные организации, которые отличаются перечнем совершаемых операций. Фактически на практике сложилась определенная дифференциация среди банков.

Для достижения цели по развитию и укреплению банковской системы России Центральный банк РФ устанавливает различные нормативы деятельности коммерческих банков. В разные периоды Банк России через установление нормативов фактически делил банки на категории, например, по величине уставного капитала [6].

Для преодоления финансового кризиса 2014 г. ряду крупных кредитных организаций были выделены средства государственной поддержки, что привело к выделению системно значимых кредитных организаций (Указание Банка России от 16.01.2014 № 3174-У «Об определении перечня системно значимых кредитных организаций»). Критерии отнесения банков к системно значимым кредитным организациям впоследствии пересматривались (Указание Банка России от 22.07.2015 № 3737-У «О методике определения системно значимых кредитных организаций»; Приказ Банка России от 20.04.2017 № ОД-1019 
«О надзоре за соблюдением системно значимыми кредитными организациями порядка использования дополнительных требований (активов) в целях расчета норматива краткосрочной ликвидности»). Отнесение банков к системно значимым кредитным организациям гарантирует им предоставление государственной поддержки во избежание банкротства (еще в 1984 г. в США был использован термин Too Big to Fail (TBTF) - «слишком крупный финансовый институт, чтобы допустить его банкротство»).

Наряду с крупными банками в России складывалась и система средних и небольших банков (региональных и муниципальных), но наблюдается тенденция вытеснения таких банков с российского финансового рыка [6;7].

Внедрение в России принципов эффективного надзора, принятых Базельским комитетом по банковскому надзору (Базель II и Базель ІІІ), также предопределило разграничение требований к банкам $[1 ; 3 ; 4]$. Так, к системно значимым кредитным организациям был применен порядок расчета краткосрочной ликвидности («Базель III») (утв. Банком России 03.12.2015 № 510-П). В то же время в отношении иных банков требуется понижение нормативных требований.

Летом 2016 г. Банк России представил для обсуждения идею реформирования банковской системы, в соответствии с которой предлагалось выделить новый вид кредитных организаций - «региональные банки». По результатам обсуждения концепция была доработана, были изменены ряд показателей и нормативов, которые планировалось применить к региональным банкам. Однако само деление банков на «региональные» и «федеральные» вызвало критику, что привело к отказу от таких названий.

\section{Переход}

\section{к пропорциональному регулированию банковской системы}

Президент РФ в своем Послании Федеральному собранию РФ в декабре 2016 г. уделил достаточное внимание развитию банковской сферы, указав, что «небольшие региональные банки, выполняющие важную функцию кредитования малого бизнеса и населе- ния, осуществляющие, как правило, самые простые банковские операции, могли бы работать по значительно упрощенным требованиям регулирования их деятельности», а «такое дифференцированное регулирование банковской системы позволит клиентам обращаться в банк, наиболее соответствующий их потребностям, а малый бизнес не будет испытывать конкуренцию за кредитные ресурсы с крупными компаниями» [8]. Банку России и Правительству РФ было поручено до 1 марта 2017 г. подготовить предложения по дифференцированному подходу к регулированию деятельности банков. Результатом этого стала подготовка и последующее принятие Федерального закона от 01.05.2017 № 92-Ф3 «О внесении изменений в отдельные законодательные акты Российской Федерации», в соответствии с которым банковская система России стала многоуровневой - появилось разделение банков - на банки с универсальной лицензией и банки с базовой лицензией.

Для банков с универсальной лицензией минимальный размер собственных средств (капитала) составит 1 млрд рублей, к ним в полном объеме будут применяться требования, предъявляемые к кредитным организациям, и при этом банк с универсальной лицензией может выполнять полный спектр банковских операций.

Для банков с базовой лицензией минимальный размер собственных средств (капитала) составит 300 млн рублей, вводятся упрощенные требования и упрощенное регулирование, и при этом банк сможет выполнять ограниченный законопроектом круг операции.

В соответствии с законом банк может изменить свой статус и преобразоваться в микрофинансовую компанию. При этом вклады, сделанные гражданами в изменившие свой статус банки, подлежат страхованию в системе обязательного страхования вкладов физических лиц в банках Российской Федерации.

Установлен переходный период - лицензия, предоставляющая кредитной организации право осуществлять банковские операции со средствами в рублях и иностранной валюте, привлекать во вклады денежные средства физических и юридических лиц в рублях и иностранной валюте (генеральная лицензия), выданная до вступления в силу закона, сохра- 
няет силу до получения банком новой лицензии. Изменившиеся требования к минимальному размеру собственных средств (капиталу) устанавливаются с 1 января 2018 г., и если банк по состоянию на 1 января 2018 г. не соответствует новым требованиям к размеру собственных средств (капиталу), то он должен изменить свой статус до 1 января 2019 года.

Применениепринципов дифференцированного подхода к требованиям, предъявляемым к кредитным организациям в зависимости от перечня банковских операций, позволит, по мнению законодателей, с одной стороны снизить издержки небольших кредитных организаций на соблюдение международных стандартов и будет способствовать повышению доступности банковских услуг на территории РФ, а с другой стороны повысит надежность крупных банков, обязующихся соблюдать требования регулятора в полном объеме.

В то же время реформа банковской системы вызывала дискуссию как в научных кругах, так и в самой банковской сфере. Так, Л.Г. Ефимова, критикуя законопроект о пропорциональном регулировании, указывает, что Банк России вправе стимулировать мелкие и средние банки обслуживать предприятия мелкого и среднего бизнеса путем применения дифференцированных экономических нормативов [5]. Президент Ассоциации российских банков Г.А. Тосунян, выступая 28 марта 2017 г. на съезде Ассоциации российских банков, подверг критике действия Банка России по проводимой им политике [2]. Итогом таких резких заявлений стало объявление о выходе из Ассоциации восьми крупнейших банков.

\section{Перспективы развития \\ банковской системы России в связи с переходом \\ к пропорциональному регулированию}

Пропорциональное регулирование банковской системы можно определить как регулирование банковской деятельности, соответствующее тем рискам, которые несут банки, в том числе понижение нормативов с одновременным ограничением в осуществлении отдельных банковских операций. Небольшие банки (банки с базовой лицензией) не будут соблюдать полностью все международные стандарты Базельского комитета по банковскому надзору, но будут ограничены в проведении операций.

С одной стороны, российская банковская система идет по пути других государств, которые уже имеют достаточный опыт работы многоуровневой банковской системы с выделением как территориальных банков, так и банков общегосударственного уровня. Опыт правового регулирования банковских систем за рубежом с учетом финансовых кризисов свидетельствует о необходимости развития усиления управления рисками кредитных организаций.

С другой стороны, действующая система банковского регулирования и надзора нацелена в большей степени на поддержание крупных, системно значимых банков, что приводит к росту концентрации в финансовом секторе и уменьшает конкуренцию. В последние годы наблюдается тенденция ограничения широкого доступа небольших банков к участию в определенных проектах. Например, ст. 176 Жилищного кодекса РФ предусматривает, что специальные счета (для размещения средств региональных фондов капитального ремонта жилья) могут открываться только в кредитных организациях, величина собственных средств (капитала) которых составляет не менее чем 20 млрд рублей. Имеются и другие ограничения для небольших банков (по работе с бюджетными средствами, субсидированием и пр.). Такие ограничения по работе некрупных кредитных организаций приводят к росту недоверия в отношении них со стороны граждан и организаций.

Вместе с тем правовое положение крупных системно значимых банков полностью не определено законодателем. Федеральный закон от 01.05.2017 № 92-Ф3 выделяет лишь категорию банков с универсальной лицензией, а определение критериев системно значимых банков так и находится на уровне Банка России.

Небольшие банки (а это примерно около 300 действующих банков) за короткий период времени должны будут существенно увеличить размер собственных средств (капитала) чтобы соответствовать требованиям закона, что приведет к уменьшению числа банков на российском финансовом рынке. 
Таким образом, следует продолжить закрепление нормативных основ разных видов банков с учетом применения зарубежного опыта, а также научного обоснования ученых в области финансового и банковского права.

\section{Выводы}

Поскольку ряд государств уже имеют сформировавшуюся банковскую систему с разделением банков на территориальные, действующие только в отдельных регионах, и банков общегосударственного уровня, целесообразно при пропорциональном регулировании банковской системы России учесть опыт других государств чтобы избежать тех ошибок, которые были допущены ранее.

Действующее российское законодательство ограничивает возможности для небольших банков по ведению банковских операций в отдельных секторах, таким образом банки с базовой лицензией будут и дальше терять свои позиции. Это может привести к неравномерному социально-экономическому развитию субъектов РФ, что окажет влияние на экономическую безопасность тех регионов, где не развиты региональные банки.

Следует прогнозировать, что применение пропорционального регулирования банковской системы в том виде, который применен законодателем, неизбежно приведет к еще большему усилению роли крупных, системно значимых банков и росту концентрации финансовых ресурсов в рамках узкого круга субъектов банковского сектора. Возрастает влияние государства на работу банков, что в свою очередь свидетельствует о необходимости усиления ответственности государства за ошибки при принятии решений по развитию и укреплению банковской системы. Оказывая поддержку системно значимым банкам за счет средств бюджета (а это деньги налогоплательщиков), государство в лице Банка России должно обосновывать целесообразность и эффективность принятия таких решений.

\section{СПИСОК ЛИТЕРАТУРЫ}

1. Борисов, О. С. Практика внедрения Базельского комитета по банковскому надзору (Базель III) в Российской Федерации / О. С. Борисов, Е. Н. Кон- драт // Правовое поле современной экономики. 2016. - № 3. - С. 122-134.

2. Выступление Г. Тосуняна на Съезде АРБ 2017. - Электрон. текстовые дан. - Режим доступа: https://arb.ru/b2b/first_person/vystuplenie g tosunyana_na_sezde_arb_2017-10104528/(дата обращения: 10.08.2017). - Загл. с экрана.

3. Гончарова, М. В. Международное соглашение Базель II: содержание и цели надзорного процесса / М. В. Гончарова // Правовая парадигма. 2017. - T. 16. № 1. - C. 158-164.

4. Гончарова, М. В. Международное соглашение Базель II: четыре принципа надзорного процесса / М. В. Гончарова // Вестник Волгоградского государственного университета. Серия 5 , Юриспруденция. - 2016. - Т. 15. № 4 (33). - С. 155-161.

5. Ефимова, Л. Г. К обсуждению концепции законопроекта о пропорциональном регулировании (или о создании многоуровневой системы) / Л. Г. Ефимова // Банковское право. - 2017. - № 3. C. 7-12.

6. Кох, Л.В.Пропорциональное регулирование: «за» и «против / Л. В. Кох, Ю. В. Кох // Ученые-экономисты Санкт-Петербурга - Петербургскому международному экономическому форуму : сб. науч. ст. СПб. : Изд-во СПбГЭУ, 2017. - С. 28-37.

7. Миронова, С. М. Муниципальные банки как инструмент развития муниципальных образований: финансово-правовые аспекты / С. М. Миронова // Бизнес. Образование. Право. Вестник Волгоградского института бизнеса. - 2017. - № 3 (40).

8. Послание Президента РФ Федеральному Собранию от 01.12.2016 // Парламентская газета. 2016. - № 45.

9. Рыбакова, С. В. Теоретические основы регулирования деятельности кредитных организаций как субъектов современного финансового права : дис. ... д-ра юрид. наук / Рыбакова Светлана Викторовна. - Саратов, 2014. $-603 \mathrm{c}$.

10. Черникова, Е. В. Публично-правовое регулирование банковской деятельности в Российской Федерации (финансово-правовые аспекты) : дис. ... д-ра юрид. наук / Черникова Елена Вадимовна. M., 2009. -432 c.

\section{REFERENCES}

1. Borisov O.S., Kondrat E.N. Praktika vnedreniya Bazelskogo komiteta po bankovskomu nadzoru (Bazel III) v Rossiyskoy Federatsii [The 3ractice of Implementation of the Basel Committee on Banking Supervision (Basel III) in the Russian Federation]. Pravovoe pole sovremennoy ekonomiki [Legal Field of Modern Economy], 2016, no. 3, pp. 122-134. 
2. Vystuplenie G. Tosunyana na Syezde ARB2017 [G. Tosunyan's Speech at the Congress of the ARB - 2017]. URL: https://arb.ru/b2b/first person/ vystuplenie_g_tosunyana_na_sezde_arb_201710104528/. (accessed August 10, 2017).

3. Goncharova M.V. Mezhdunarodnoe soglashenie Bazel II: soderzhanie i tseli nadzornogo protsessa [International Agreement Basel II: Content and Objectives of the Oversight Process]. Pravovaya paradigma [Legal Concept], 2017, vol. 16, no. 1, pp. 158-164.

4. Goncharova M.V. Mezhdunarodnoe soglashenie Bazel II: chetyre printsipa nadzornogo protsessa [International Agreement Basel II: Four Principles of the Supervisory Process]. Vestnik Volgogradskogo gosudarstvennogo universiteta. Seriya 5, Yurisprudentsiya [Science Journal of Volgograd State University. Jurisprudence], 2016, vol. 15, no. 4 (33), pp. 155-161.

5. Efimova L.G. K obsuzhdeniyu kontseptsii zakonoproekta o proportsionalnom regulirovanii (ili o sozdanii mnogourovnevoy sistemy) [Discussion of the Concept of the Draft Law on Proportional Control (or on the Creation of a Multi-Level System)]. Bankovskoe pravo, 2017, no. 3, pp. 7-12.

6. Kokh L.V., Kokh Yu.V. Proportsionalnoe regulirovanie: «za» $\mathrm{i}$ «protiv» [Proportional Control: "For" and "Against"]. Uchenye-ekonomisty SanktPeterburga - Peterburgskomu mezhdunarodnomu ekonomicheskomu forumu: sb. nauch. st. [Scientists
Economists of Saint Petersburg - to the Saint Petersburg International Economic Forum. Collection of Scientific Articles]. Saint Petersburg, Izd-vo SPbGEU, 2017, pp. 28-37.

7. Mironova S.M. Munitsipalnye banki kak instrument razvitiya munitsipalnykh obrazovaniy: finansovo-pravovye aspekty [Municipal Banks as a Tool of Community Development: Financial and Legal Aspects]. Biznes. Obrazovanie. Pravo. Vestnik Volgogradskogo instituta biznesa [Education. Right. Bulletin of the Volgograd Institute of Business], 2017, no. 3 (40).

8. Poslanie Prezidenta RF Federalnomu Sobraniyu of 01.12.2016 [The Message of the President of the Russian Federation to the Federal Assembly of December 1, 2016]. Parlamentskaya gazeta, 2016, no. 45.

9. Rybakova S.V. Teoreticheskie osnovy regulirovaniya deyatelnosti kreditnykh organizatsiy kak subyektov sovremennogo finansovogo prava: dis. ... d-ra yurid. nauk [Theoretical Bases of Regulating the Activity of Credit Organizations as Subjects of Modern Financial Law. Dr. jurid. sci. diss.]. Saratov, 2014. 603 p.

10. Chernikova E.V. Publichno-pravovoe regulirovanie bankovskoy deyatelnosti $v$ Rossiyskoy Federatsii (finansovo-pravovye aspekty): dis. ... d-ra yurid. nauk [Public-Legal Regulation of Banking Activities in the Russian Federation (Financial and Legal Aspects). Dr. jurid. sci. diss.]. Moscow, 2009. 432 p.

\section{Information about the Author}

Svetlana M. Mironova, Candidate of Juridical Sciences, Associate Professor, Department of Constitutional and Administrative Law, Volgograd Institute of Management - Volgograd branch of RANEPA, Gagarina St., 8, 8400131 Volgograd, Russian Federation, smironova2017@gmail.com.

\section{Информация об авторе}

Светлана Михайловна Миронова, кандидат юридических наук, доцент кафедры конституционного и административного права, Волгоградский институт управления - Волгоградский филиал РАНХиГС, ул. Гагарина, 8, 400131 г. Волгоград, Российская Федерация, smironova2017@gmail.com. 